\title{
USO DE MARCADORES Y SELECCIÓN DE GAMETOS PARA EL MEJORAMIENTO SIMULTÁNEO DE CARACTERES MÚLTIPLES DE FRIJOL (Phaseolus vulgaris L.) PARA MESOAMÉRICA Y EL CARIBE1
}

\author{
Shree P. Singh ${ }^{2}$
}

\begin{abstract}
RESUMEN
Uso de marcadores y selección de gametos para el mejoramiento simultáneo de caracteres múltiples de frijol (Phaseolus vulgaris L.) para Mesoamérica y el Caribe. El objetivo fue describir requerimientos básicos y métodos alternativos de selección para el mejoramiento simultáneo en frijol común, en el tiempo más corto posible y considerando el máximo número de caracteres agronómicos. Esta estrategia incluye: (1) obtener claridad sobre la importancia y problemática del cultivo de frijol para la zona, (2) fijar objetivos y prioridades del mejoramiento genético, (3) identificar y usar únicamente padres que con absoluta confianza pueden considerarse donantes de genes necesarios, (4) utilizar cruzamientos múltiples con un número adecuado de polinizaciones para producir suficiente semilla de cada cruza, (5) realizar evaluación y selección para marcadores actualmente disponibles (e.g., para gorgojo, mosaico común, mosaico dorado, antracnosis, picudo, bacteriosis común y roya, entre otros) desde la etapa de hibridación, (6) métodos alternativos de selección; como selección de gametos y descendiente de semilla única (SG-DSU), selección de gametos y pedigrí usando marcadores (SG-PUM), selección de gametos y evaluación y selección agronómica de familias en generaciones tempranas (SG-EAF), o una combinación e integración de los métodos SG-PUM y SG-EAF; y (7) conseguir una estrecha y genuina colaboración e integración de actividades de mejoramiento entre diferentes investigadores a nivel de instituciones, países y la región entera, en localidades claves, para efectuar evaluaciones confiables de viveros de frijol a efectos de realizar selección simultánea para el máximo número de caracteres agronómicos.
\end{abstract}

\begin{abstract}
Use of molecular markers and gamete selection for simultaneous improvement of multiple characters in the common bean (Phaseolus vulgaris L.) for middle America and the Caribbean. The objective is to describe the basic requirements and alternative selection methods for simultaneous improvement of maximum number of agronomic characters in the shortest time possible. This strategy includes: (1) deterrnination of the importance and priorities of bean production problems in the region, (2) definition of objectives and priorities of breeding, (3) identification and use of reliable parental sources considered to be donors of necessary genes, (4) development of multipleparent crosses with large number of pollinations to produce sufficient seed of each cross, (5) evaluation and selection for currently available markers (e.g., for zabrotes, bean common mosaic, bean golden mosaic, rust, anthracnose, apion, common bacterial blight, etc.) from hybridization, (6) alternative selection methods such as gamete selection and single seed descendants (GS-SSD), gamete and pedigree selection using markers (GS-PUM), gamete selection and agronomic evaluation and selection of families in early generations (GS-AEF), or a combination and integration of the GS-PUM and GS-AEF methods; and (7) seeking genuine and direct collaboration and integration in all activities of researchers from different disciplines, institutions, countries and the entire region at key sites foro reliable evaluation of bean nurseries in order to carry out simultaneous selection for a maximum number of agronomic traits.
\end{abstract}

1 Presentado en la XLIII Reunión Anual del PCCMCA, Panamá, 1997

2 Centro Internacional de Agricultura Tropical (CIAT), A.A. 6713, Ca!i, Colombia. Email: s.singh@cgnet.com 


\section{INTRODUCCIÓN}

\section{El frijol y sus problemas}

En los países de Mesoamérica y el Caribe se cultivan mas de 500,000 ha de frijol (Phaseolus vulgaris L.) de semilla pequeña de origen Mesoamericano (principalmente negros y rojos), y más de 200,000 ha de semilla grande de origen Andino (principalmente rojo moteado y rojos). Entre los principales problemas del cultivo se incluyen mosaico común (MC), mosaico dorado (MD), bacteriosis común (BC), mancha angular (MA), antracnosis, roya, mustia hilachosa $(\mathrm{MH})$, picudo, salta hojas, gorgojos, baja fertilidad del suelo y sequía.

El mejoramiento de los frijoles de semilla pequeña ha recibido comparativamente más atención. Consecuentemente, cultivares de semilla negra y roja con resistencia a MC, MD, picudo, BC, MH y salta hoja fueron desarrollados (Beebe et al., 1993; 1995). En los frijoles de semilla grande los logros en el ámbito de producción todavía no son muy notables. Esto en parte se debe a los pocos profesionales dedicados al mejoramiento en este tipo de frijol. Además, aunque ya existen líneas avanzadas con resistencia a MC, MD, roya, salta hojas y BC todavía no se ha notado el impacto de estos avances en el ámbito de la producción. A pesar de los logros conseguidos, subsiste la necesidad de desarrollar cultivares con resistencias múltiples (tres o más factores), con alto rendimiento, precocidad y de tipo de semilla comercial, en ambos tipos de frijol.

Teniendo en cuenta la urgencia de obtener lo más pronto posible cultivares con caracteres múltiples deseables, la escasez de los recursos necesarios y la reducida capacidad de realizar mejoramiento genético por separado para cada país, el objetivo es discutir los requerimientos básicos y proponer métodos alternativos de mejoramiento simultáneo de caracteres múltiples en el tiempo más corto posible.

\section{Requerimientos básicos para mejoramiento de frijol para Mesoamérica y el Caribe}

Debido a problemas en recuperar caracteres agronómicos esenciales (calidad de semilla, madurez, rendimiento), la necesidad de incorporar resistencias pertinentes para cada situación, los diferentes estados de mejoramiento en el que se encuentran distintos tipos de frijol, las diferencias entre países involucrados y las zonas donde se cultivan frijoles, es necesario perseguir un mejoramiento separado para cada tipo de frijoles importantes. Además, por ser el proceso de mejoramiento costoso y de largo plazo, deben participar únicamente países con programas de mejoramiento establecidos e investigadores honestos, serios y dedicados. La com- plementación e integración entre investigadores al nivel de la región para evaluación de los padres, poblaciones y familias segregantes y líneas avanzadas con el fin de generar información confiable y necesaria a tiempo, es sumamente crítica.

\section{Etapas en el desarrollo y adopción de cultivares nue- vos de frijol común}

La tarea de buscar solución genética a los problemas de producción del cultivo de frijol a través del mejoramiento genético y llevarla hasta los productores puede ser dividida en las siguientes etapas (Cuadro 1).

1. Mejoramiento per se y desarrollo de líneas avanzadas.

2. Evaluación de líneas avanzadas, pruebas con agricultores e identificación de nuevos cultivares.

3. Aumento de semilla, determinación del manejo agronómico y difusión de cultivares.

4. Medición y documentación de los impactos en aumentar la producción, bajar costo de producción e impacto ambiental y social.

5. Publicación de los resultados y progreso genético.

Teniendo en cuenta el tema principal de este artículo de todas estas etapas discutiremos únicamente el mejoramiento per se y desarrollo de líneas avanzadas, sin embargo, es necesario aclarar que una falla o incumplimiento en cualquier etapa debe ser considerada como una falla total del proceso de mejoramiento.

\section{Mejoramiento per se y desarrollo de líneas avanza- das}

Para tener claridad y asegurar el éxito del mejoramiento genético y desarrollo de líneas avanzadas por uso de marcadores y selección por gametos se debe considerar lo siguiente:

1. Objetivos y prioridades del mejoramiento.

2. Búsqueda e identificación de padres donantes de genes necesarios - VIPADOGEN.

3. Selección de padres y planificación de cruzamientos.

4. Marcadores disponibles y selección por gametos durante la hibridación.

5. Derivación de familias $\mathrm{F}_{2}$ de plantas $\mathrm{F}_{1}$ seleccionadas.

6. Métodos alternativos de manejo o de evaluación y selección de familias seleccionadas y derivadas de $\mathrm{F}_{1}$ para desarrollar líneas avanzadas.

\section{Objetivos y prioridades del mejoramiento}

Inicialmente se enfatizó el mejoramiento para resistencia a MC y MD en los frijoles de semilla peque- 
Cuadro 1. Uso de marcadores y selección de gametos para mejoramiento simultáneo de caracteres múltiples en frijol común.

- Claridad de objetivos y prioridades de mejoramiento

$\downarrow$

- Evaluación exhaustiva y rigurosa de padres donantes y cultivares para mejorar

- Cruzamientos múltiples y selección por marcadores durante hibridación

- Derivación de familias $F_{2}$ de plantas individuales $F_{1}\left(F_{1.2}\right)$ seleccionadas

- Evaluación e identificación de familias promisorias $\left(\mathrm{F}_{1.2}-\mathrm{F}_{1.4}\right)$

- Desarrollo de líneas avanzadas $\left(\mathrm{F}_{5}-\mathrm{F}_{7}\right)$

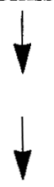

- Evaluación de líneas avanzadas para selección de nuevos cultivares

Viveros de adaptación y complementarios

Ensayos de rendimiento bajo presión de estreses bióticos y abióticos

Pruebas con agricultores y aumento de semilla

Manejo agronómico fomentando la conservación y el uso eficiente de los recursos naturales

Recomendación y difusión de nuevos cultivares y prácticas agronómicas

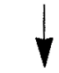

- Medición y documentación de los impactos: productividad, ambiental y social (PAS)

ña, seguido por resistencia a BC, MH y picudo a través de proyectos separados para cada uno. Con base en los logros ya alcanzados, existe una necesidad de desarrollar cultivares con resistencias múltiples en el futuro. Por ejemplo, en el futuro inmediato para frijoles de semilla pequeña rojo y negro se deben combinar resistencias a MC, MD, BC, picudo, MA y gorgojo. Para frijoles de semilla grande la combinación de resistencias a $\mathrm{MC}, \mathrm{MD}$, roya, $\mathrm{BC}$ y gorgojo debe ser prioritaria para este ciclo de mejoramiento.

\section{Búsqueda e identificación de padres donantes de ge- nes necesarios - VIPADOGEN}

La identificación de padres con alta resistencia, probada a través de evaluaciones repetidas en diferentes localidades y años contrastantes para problemas principales como MD, MA, picudo, $\mathrm{BC}$, antracnosis y roya, es sumamente esencial para asegurar el éxito en el mejoramiento genético. Estos padres pueden ser identificados de viveros específicos (e.g., de roya, picudo, antracnosis) y/o de un vivero especial agrupando algunos padres para cada factor escogido de la información previamente disponible. Por ejemplo entre 1993 y 1996 se distribuyeron desde CIAT dos viveros de este tipo a algunos países de Mesoamérica y el Caribe. Para factores como antracnosis, MA y roya, además de las evaluaciones realizadas en campo se deben verificar las resistencias en invernaderos y laboratorios. Desdichadamente para Mesoamérica y el Caribe todavía no se ha generado la información necesaria para escoger padres para cruzamientos con cierto grado de confianza para la mayoría de los factores limitantes. En el Cuadro 2 se incluye algunas fuentes de genes necesarios.

\section{Selección de padres y planificación de cruzamientos}

Una vez que se tiene la información necesaria sobre rendimiento, adaptación, días a madurez, reacción a estrés hídrico y baja fertilidad del suelo, además de las reacciones a enfermedades y plagas de los cultivares a mejorar, líneas elites y otros padres donantes, se deben seleccionar y agrupar padres en las combinaciones que se van a cruzar. En otras palabras, se debe planificar las cruzas finales y las cruzas anteriores necesarias para la formación de estas cruzas finales. Para realizar este tra- 
Cuadro 2. Algunos padres donantes de genes útiles en frijol común.

\begin{tabular}{llcllc}
\hline Identificación & Color semilla & Hábito & \multicolumn{1}{c}{ Raza } & Caracter & Gen \\
\hline A 429 & Pinto & II & Durango & Mosaico dorado & bgml \\
DOR 482 & Rojo & II & Mesoamérica & Mosaico dorado & bgml \\
CATRACHITA & Rojo & II & Mesoamérica & Antracnosis & Co5 \\
SEL. 1360 & Negro & III & Mesoamérica & Antracnosis & Co6 \\
IVT 7214 & Blanco & III & Mesoamérica & Mosaico común & bc3 \\
G 17341 & Pinto & III & Durango & Bacteriosis & - \\
G 18484 & Negro & II & Mesoamérica & Bacteriosis & - \\
WILKINSON 2 & Blanco & I & Nueva Granada & Bacteriosis & - \\
XAN 309 & Rojo & II & Mesoamérica & Bacteriosis & - \\
J 117 & Rosado rayado & IV & Jalisco & Picudo & Agr \\
RAZ 44 & Blanco & III & Mesoamérica & Gorgojo & Arl \\
\hline
\end{tabular}

bajo se debe tener en cuenta la distancia genética entre los padres involucrados en cada cruza, sus relaciones y origen evolucionario como acervo y razas de frijol, tipo de semilla, hábito de crecimiento, madurez, etc., además de los genes útiles de resistencia que van a aportar. Ejemplos para frijoles negros y rojos para Mesoamérica y rojo moteado para el Caribe son los siguientes:

DOR 390 x [(RAZ 44 x J 117) x (A 429 x G 18484)]

Rojo de Seda x [(IVT 7214 x XAN 309) x (DOR 482 x De Celaya)]

PC 50 x [(WILK 2 x PVA 8OGA) x (DOR 482 x PVA 773)]

Para asegurar un muestreo adecuado de los genes necesarios o alelo favorables aportados por cada padre involucrado en cruzamientos se debe hacer polinización planta - a - planta en pares entre las hembras y machos. Además, se debe producir suficiente semilla híbrida $F_{1}$ de cada cruzamiento. En nuestro programa generalmente producimos unas 50 semillas $\mathrm{F}_{1}$ por cada cruza simple y mas de 200 semillas por las cruzas triple, doble y múltiples. El total de número de cruzamientos finales planificados debe ser proporcional a las necesidades y recursos disponibles para evaluaciones y selecciones posteriores.

\section{Marcadores disponibles y selección por gametos du- rante la hibridación}

En el caso del cultivo de frijol, los marcadores dominantes para caracteres agronómicos son de diversa naturaleza: morfológicos, como hábito de crecimiento; reacción a enfermedades, como antracnosis, roya y MC; tipo de proteína en semilla, como arcelina para resistencia a gorgojo; y moleculares de base DNA, como RFLP, RAPD, SCAR y ASAP. Del último grupo ya están disponibles (Adam-Blandon et al., 1994; Gu et al.,
1994; Haley et al., 1993 y 1994; Johnson et al., 1995; Jung et al., 1996; Kelly y Miklas, 1997; Miklas et al., 1993 y 1996; Nodari et al., 1993; Urrea et al., 1996) los marcadores para MC, MD, picudo, antracnosis, roya y BC entre otros (Cuadro 3). Para todos los caracteres dominantes como hábito de crecimiento, resistencia a antracnosis, roya, MC, presencia de arcelina en semilla y marcadores moleculares dominantes y codominantes, se debe empezar la selección durante la hibridación (Singh, 1994). Por ejemplo, las semillas $F_{1}$ de la cruza doble [(RAZ 44 x J 117) x (A 429 x G 18484)] utilizada para cruzar con DOR 390 pueden ser seleccionadas para arcelina. Por ser un carácter dominante, únicamente el $50 \%$ de las semillas poseerán arcelina y ellas deben ser evaluadas posteriormente para los marcadores disponibles para MD, BC y picudo. Así entonces únicamente $1 / 16$ de todas las semillas $F_{1}$ de cruza doble va a portar los genes necesarios para resistencias a cuatro factores. Aunque es una labor muy dirigida y costosa, inicialmente esto asegura incorporación de cuatro caracteres a la vez en DOR 390 y además reduciría el tamaño de población en $\mathrm{F}_{2}$ a un 1/256 de lo que estaría obligado a llevar si no se hubiera hecho evaluación y selección de $\mathrm{F}_{1}$ de la cruza doble y de la final, antes y después de haber cruzado con DOR 390.

\section{Derivación de familias $F_{2}$ de plantas $F_{1}$ selecciona- das}

Las plantas $\mathrm{F}_{1}$ de cruzamientos finales ya seleccionadas por marcadores dominantes y codominantes deben ser cosechadas separadamente. Así el total de familias $F_{2}$ proveniente de cada cruzamiento debe ser igual a las plantas $F_{1}$ seleccionada. Estas familias derivadas de $F_{1}$ posteriormente pueden ser sometidas a evaluación y selección usando diferentes métodos de mejoramiento para desarrollar líneas avanzadas. 
Cuadro 3. Marcadores moleculares (RAPO) disponibles para algunos genes útiles en frijol común.

\begin{tabular}{llll}
\hline Gene & \multicolumn{1}{c}{ Fuente } & Caracter & Marcador \\
\hline Ur 32 & PI 181996 & Roya & OAC20 \\
& & & OAE19 \\
Ur 4 & Early Gallatin & Róa & OA14 \\
Ur 5 & Mexico 309 & Roya & OF10 \\
& & & OI19 \\
Co 1 & Michigan OR Kidney & Antracnosis & OF10 \\
Co 5 & G 2333, SEL 1360 & Antracnosis & OAB3 \\
Co 6 & AB 136, Catrachita & Antracnosis & OAH1 \\
& & & OAK20 \\
Y & Seafarer Montcalm & Mosaico común & OW13 \\
bc 3 & B85009 MCR 2205 & Mosaico común & OAD19 \\
& & & OC20 \\
& & & OC11 \\
bgm 1 & Garrapato, A 429 & Mosaico dorado & OR2 \\
& & & OR2 \\
& & & DOR 482 \\
\hline
\end{tabular}

Fuente: Adaptado de Kelly y Miklas, 1997.

\section{Métodos alternativos de mejoramiento para desa- rrollar líneas avanzadas}

Se describen los siguientes tres métodos alternativos para desarrollar líneas avanzadas de familias (F1.2) derivadas de plantas $\mathrm{F}_{1}$ seleccionadas. Aún no se sabe cuál de los tres métodos es el más eficiente, económico y apto para cada situación. Además, la escogencia dependería, entre otras cosas, del número de cruzamientos y familias dentro de cada cruzamiento que se tienen que evaluar y seleccionar, de la sincronización entre evaluación para marcadores y caracteres cuantitativos para los cuales no se puede utilizar marcadores al momento, y de la disponibilidad de recursos.

\section{Descendiente de semilla única (SG-DSU)}

Se utilizó el método de mejoramiento de Brim (1966); donde se deben sembrar todas las semillas obtenidas de cada una de las familias $\mathrm{F}_{2}$ derivadas de plantas $\mathrm{F}_{1}\left(\mathrm{~F}_{1.2}\right)$ seleccionadas por marcadores de cruzamientos finales, en surcos separados, en un ambiente sin estrés (Cuadro 4). Se numera y cosecha cada planta individualmente dentro de cada familia $F_{1.2}$ Luego se siembra de 10-15 semillas de cada planta en F3 (F1.2.3) en un surco de un metro de largo en campo de cuatro a cinco semillas en una maseta en invernadero. Cosechar una planta de cada surco o maseta y volver a sembrar en un surco de un metro de largo en campo o en una maseta en F4 ( $\left.F_{1.2 .3 .4}\right)$. Se cosecha una planta de cada surco ó maseta. Se selecciona por tipo de semilla co- mercial. Se siembra de 10-15 semillas de plantas seleccionadas en $\mathrm{F}_{4}\left(\mathrm{~F}_{1.2 .3 .4 .5}\right)$. Se cosecha una planta de cada surco o maseta con tipo de semilla comercial. Se siembran todas las semillas de las plantas seleccionadas $\left(F_{1.2 .3 .4 .5 .6}\right)$. Se verifica para uniformidad de color de flor, hábito de crecimiento, madurez y tipo de semilla comercial. Se cosechan masalmente todas las plantas dentro de cada uno de los surcos uniformes $\left(\mathrm{F}_{1 \text { 1.2.3.4.5.6.7 }}\right)$. Se evalúan las líneas $\left(\mathrm{F}_{7}\right)$ para marcadores, caracteres agronómicos y aumentar semillas para evaluaciones posteriores en viveros de adaptación, ensayos de rendimiento, etc., para identificación de nuevos cultivares.

\section{Pedrigrí usando marcadores (SG-PUM)}

En el método de Pedigrí usando marcadores (SGPUM) (Cuadro 5) las progenies de todas las familias $\mathrm{F}_{1.2}$ provenientes de plantas $\mathrm{F}_{1}$ seleccionadas por marcadores de cruzamientos finales, serán otra vez evaluadas por los marcadores. Unicamente las progenies seleccionadas por marcadores serán avanzadas a la siguiente generación hasta llegar a homocigocidad para todos los marcadores. Una vez logrado esto, se debe seleccionar el tipo de semilla comercial dentro de familias. La semilla seleccionada debe sembrarse espaciadamente. Las plantas así seleccionadas deben cosecharse individualmente para prueba de progenies. Las líneas uniformes por color de flor, hábito de crecimiento, madurez y tipo de semilla, deben cosecharse masalmente. Cada línea avanzada así desarrollada, será sometida a 
Cuadro 4. Descendiente de semilla única (SG-DSU).

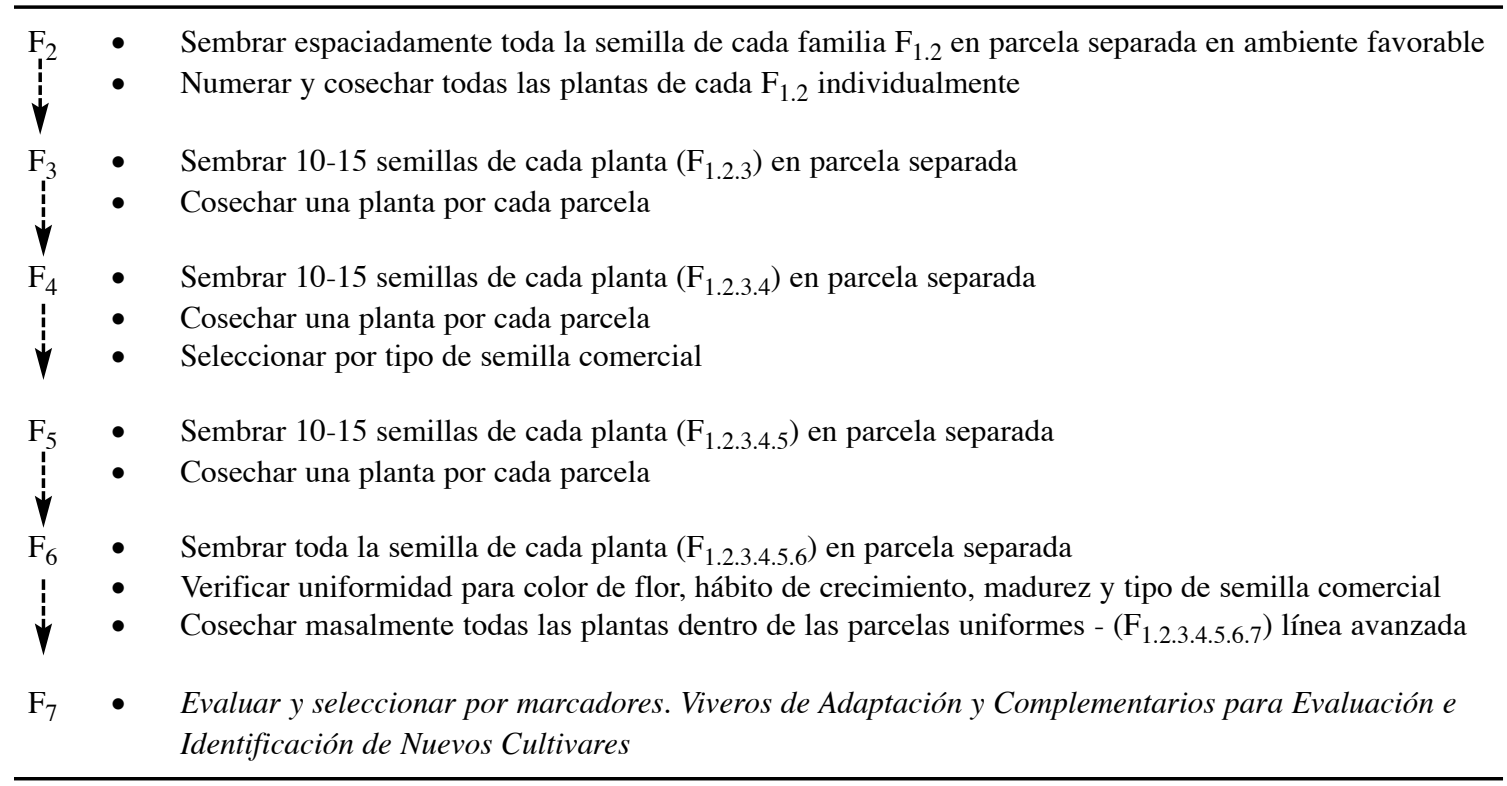

Cuadro 5. Pedigrí usando marcadores (GS-PUM).

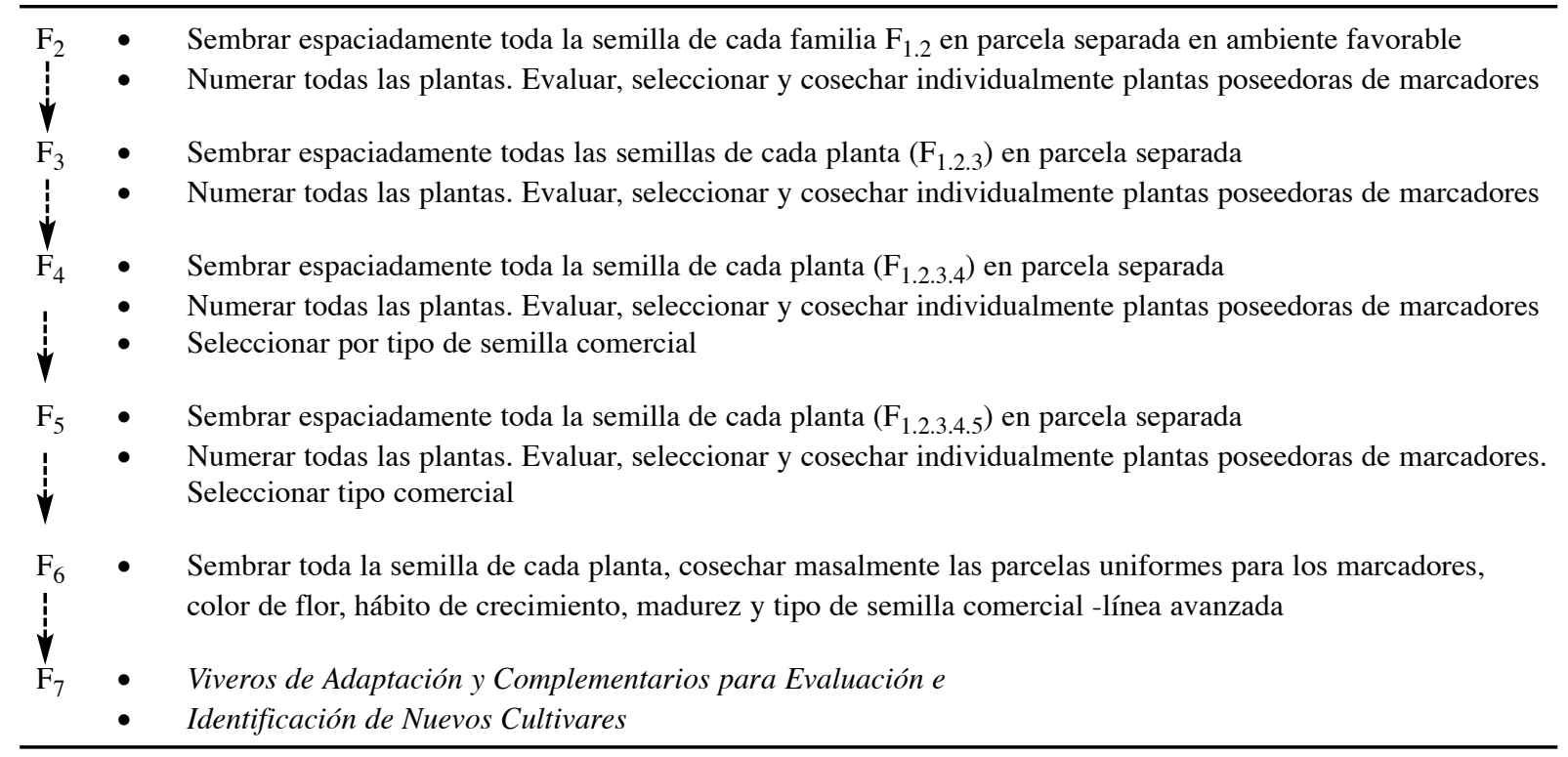


evaluación en viveros de adaptación, complementarios, ensayos de rendimiento, etc. para evaluación por separado para cada uno de los factores bióticos y abióticos a efectos de identificar nuevos cultivares.

\section{Evaluación agronómica de familias (SG-EAF)}

En la evaluación agronómica de familias (SGEAF) se siembra toda la semilla de familias $\left(\mathrm{F}_{1.2}\right)$ provenientes de plantas $\mathrm{F}_{1}$ seleccionadas por marcadores de cruzamientos finales en campo en localidad y época representativa bajo presión de factores bióticos y/o abióticos (Cuadro 6). Seleccionar entre y dentro de cada $\mathrm{F}_{1.2}$ y cosechar masalmente las plantas seleccionadas dentro de cada familia $\mathrm{F}_{1.2}$ seleccionada. Repetir la evaluación en $\mathrm{F}_{3}\left(\mathrm{~F}_{1.3}\right)$ usando parcelas de mayor tamaño y con replicaciones (Singh, 1994; Singh y Urrea, 1995; Terán y Singh, 1997). Otra vez seleccionar entre y dentro de $\mathrm{F}_{1.3}$ y cosechar masalmente plantas seleccionadas de cada familia. Evaluar las $\mathrm{F}_{1.4}$ seleccionadas en ensayos replicados en máximo número de ambientes necesarios para poder seleccionar las mejores $\mathrm{F}_{1.4}$ familias. Seleccionar para tipo de semilla comercial antes de sembrar espaciadamente las familias $\mathrm{F}_{1.5}$ promisorias. Evaluar, seleccionar y cosechar plantas individualmente dentro de cada $\mathrm{F}_{1.5}$ seleccionadas. Realizar prueba de progenie en $\mathrm{F}_{6}\left(\mathrm{~F}_{1.5 .6}\right)$ y cosechar masalmente todas las plantas de líneas uniformes para color de flor, hábito de crecimiento, madurez, tipo de semilla comercial y caracteres para los cuales fue evaluada. Someter las líneas así desarrolladas a evaluaciones en viveros de adaptación, ensayos de rendimiento, etc., para identificación de nuevos cultivares.

Se deben utilizar viveros y localidades complementarias cuando no es factible realizar evaluaciones para todos los factores en un sólo vivero o localidad durante el proceso de evaluación y selección desde $\mathrm{F}_{1.2}$ hasta $\mathrm{F}_{1.4}$. Para caracteres cuantitativos incluyendo rendimiento, bajo estrés hídrico y baja fertilidad del suelo las evaluaciones deben ser efectuadas en ambientes contrastantes, usando tamaños de parcelas y replicaciones adecuadas. Así también se debe estudiar la posibilidad de combinar los métodos SG-PUM y SG-EAF para poder aumentar la ganancia genética y la eficiencia de selección.

\section{Evaluación de líneas avanzadas para identificación de nuevos cultivares}

Aunque la evaluación de líneas avanzadas para identificación de nuevos cultivares no será discutido detalladamente, hay que enfatizar que se deben aumentar las semillas de todas las líneas desarrolladas en cantidades suficientes para permitir una evaluación sistemática, exhaustiva y rigurosa (Cuadro 7). El uso de viveros de adaptación, complementarios, ensayos replicados de rendimiento en ambientes contrastantes con y

Cuadro 6. Evaluación agronómica de familias (GS-EAF).

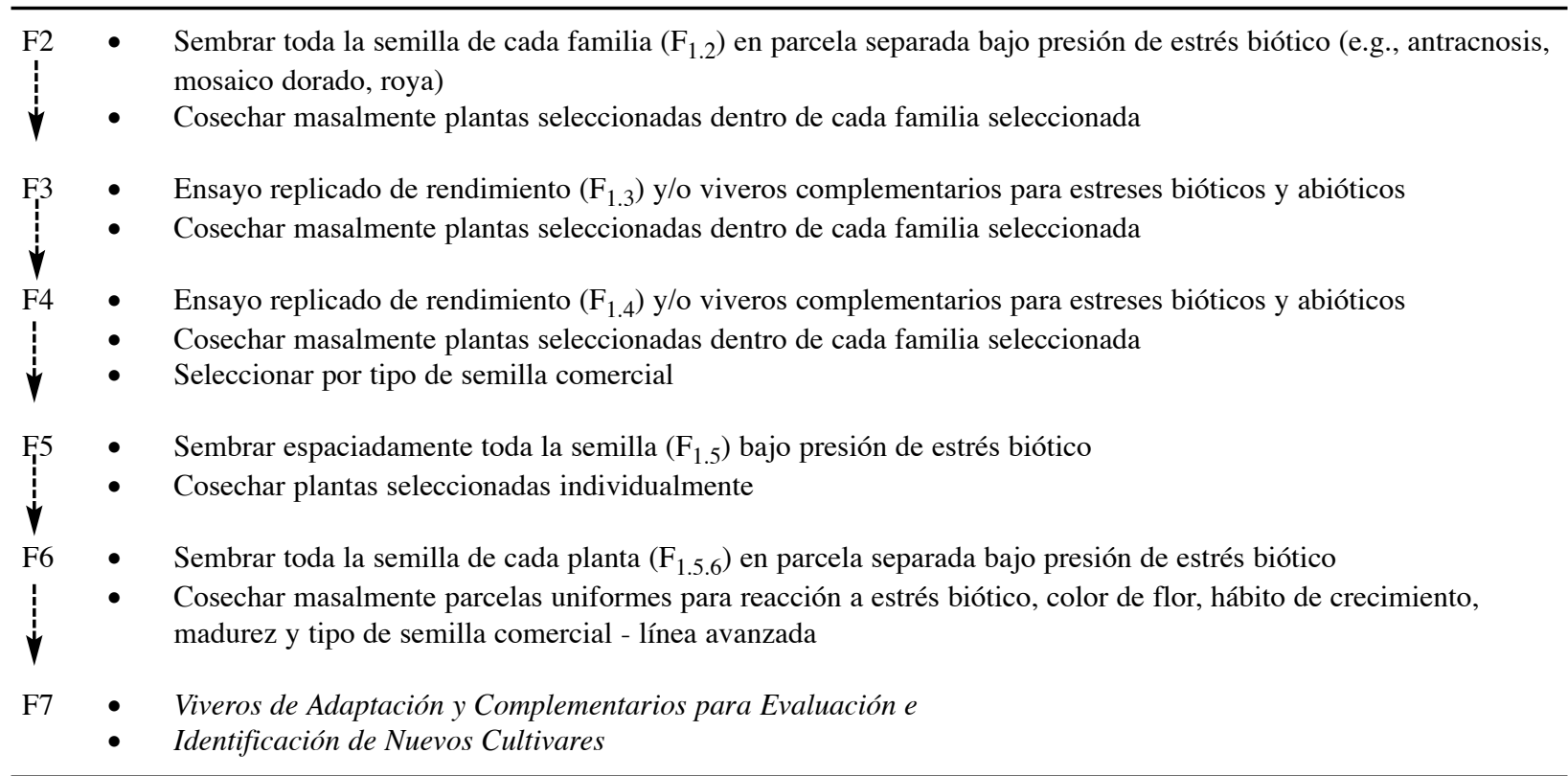


Cuadro 7. Evaluación de líneas avanzadas, pruebas con productores e identificación de nuevos cultivares.

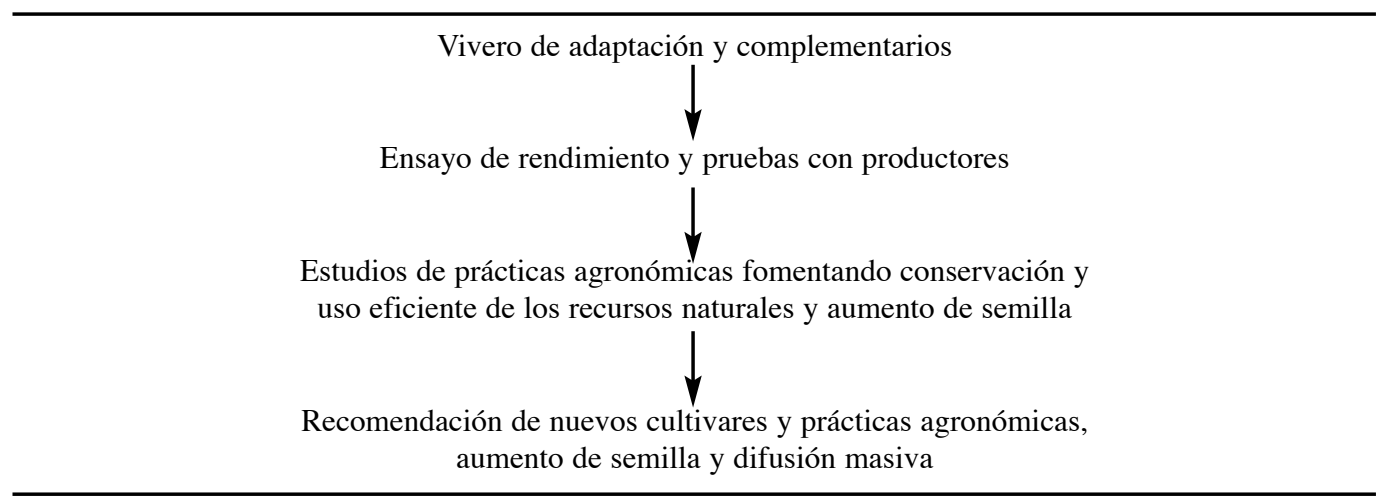

sin estrés hídrico, con y sin estrés para baja fertilidad del suelo, evaluaciones para enfermedades y plagas en invernaderos y laboratorios y pruebas con agricultores, son necesarios para poder identificar cultivares nuevos verdaderamente superiores. Su pronta y masiva adopción, ha de aumentar la productividad y bajar los costos de producción, logrando un impacto social y ambiental favorable.

\section{AGRADECIMIENTO}

Quiero expresar mis más sinceros agradecimientos a Isabel Cristina Giraldo por su ayuda tipográfica y a Oswaldo Voysest por su ayuda editorial.

\section{LITERATURA CITADA}

ADAM-BLANDON, A.E; SEVIGNAC, M.; DRON, M.; BANNEROT, H. 1994. A genetic map of common bean to localize specific resistance gene against anthracnose. Genome 37:915-924.

BEEBE, S.; CARDONA, c.; DÍAZ, O.; RODRÍGUEZ, E; MANCIA, E.; AJQUEJAY, S. 1993. Development of common bean (Phaseolus vulgaris L.) lines resistant to the pod weevil, Apion godmani Wagner, in Central America. Euphytica 69:83-88.

BEEBE, S.E.; OCHOA, 1.; SKROCH, P.; NIENHUIS, J.; TIVANG, J. 1995. Genetic diversity among common bean breeding lines developed for Central America. Crop Sci. 35:1178-1183.
BRIM, C.A. 1966. A modified pedigree method of selection in soybeans. Crop Sci. 6:220.

GU, W.K.; WEEDEN, N.E; ZHU, J.Q.; WALLACE, D.H. 1994. Identification of a DNA marker for $\mathrm{Hr}$, a gene that interacts with ppd to confer extreme photoperiod sensitivity in common bean. Annu. Rpt. Bean Improv. Coop.37:125-126.

HALEY, S.D.; AFANADOR, L.; KELLY, J.D. 1994. Identification and application of a random amplified polymorphic DNA marker for the I gene (Potyvirus resistance) in common bean. Phytopathology 84:157-160.

HALEY, S.D.; MIKLAS, P.N.; STAVELY, JR; BYRUM, J.; KELLY, J.D. 1993. Identification of RAPD markers linked to a major rust resistance gene block in common bean. Theor. Appl. Genet. 86:505-512.

JOHNSON, E.; MIKLAS, P.N.; STAVELY, J.R.; MARTÍNEZ-CRUZADO, J.C. 1995. Coupling and repulsion phase RAPDs for marker assisted selection of PI 181996 rust resistance in common bean. Theor. Appl. Genet. 90:659-660.

JUNG, G.; COYNE, D.P.; SKROCH, P.w.; NIENHUIS, J.; ARNAUD-SANTANA, E.; BOKOSI, J.; ARIYARATHNE, H.M.; STEADMAN, J.R. 1996. Molecular markers associated with plant architecture and resistance to common blight, web blight and rust in common bean. J. Amer. Soco Hort. Sci. 121:794-803.

KELLY, J.D.; MIKLAS, P.N. 1997. The role of molecular markers in breeding for qualitative and quantitative traits of common bean. In: S.P. Singh and O. Voysest (eds.). Proceedings of "Taller de Mejoramiento de frijol 
para el Siglo XXI": Bases para una estrategia para América Latina. CIAT, Cali, Colombia (in press).

MIKLAS, P.N.; AFANADOR, L.; KELLY, J.D. 1996. Recombination facilitated RAPD marker assisted selection for disease resistance in common bean. Crop Sci. 36:86-90.

MIKLAS, P.N.; STAVELY, J.R.; KELLY, J.D. 1993. Identification and potential use of a molecular marker for rust resistance in common bean. Theor. Appl. Genet. 85:745-749.

NODARI, R.O.; TSAI, S.M.; GUZMAN, P.; GILBERTSON, R.L.; GEPTS, P. 1993. Toward an integrated linkage map of common bean. III. Mapping genetic factors controlling host-bacteria interactions. Genetics 134: 341-350.
SINGH, S.P. 1994. Gamete selection for simultaneous improvement of multiple traits in common bean. Crop Sci. $34: 352-355$

SINGH, S.P.; URREA, C.A. 1.995. Inter- and intraracial hybridization and selection for seed yield in early generations of common bean. Euphytica 81: 131-137.

TERÁN, H.; SINGH, S.P. 1997. Pruebas de rendimiento de frijol común en generaciones tempranas. Resúmenes XLIII Reunión Anual PCCMCA, Panamá. p.94.

URREA, C.A.; MIKLAS, P.N.; BEAVER, J.S.; RILEY, R.H. 1996. A codominant randomly amplified polymorphic DNA (RAPD) marker useful for indirect selection of bean golden mosaic virus resistance in common bean. J. Amer. Soco Hort. Sci. 121:1035-1039. 